\title{
Predicting the vertical location of branches along Atlas cedar stem (Cedrus atlantica Manetti) in relation to annual shoot length
}

\author{
François COURBET $^{\mathrm{a} *}$, Sylvie SABATIER ${ }^{\mathrm{b}}$, Yann GUÉDON $^{\mathrm{c}}$ \\ ${ }^{a}$ INRA, Unité de Recherches forestières méditerranéennes, Domaine Saint Paul, Site Agroparc, 84914 Avignon Cedex 9, France \\ b Unité CIRAD - CNRS - INRA - IRD - Université Montpellier 2 "botanique et bioinformatique de l'architecture des plantes" TA40/PS2, \\ Boulevard de la Lironde, 34398 Montpellier Cedex 5, France \\ ${ }^{c}$ CIRAD, UMR DAP and INRIA, Virtual Plants, TA 40/02, 34398 Montpellier Cedex 5, France
}

(Received 8 September 2006; accepted 19 February 2007)

\begin{abstract}
A model for the vertical location of whorl and interwhorl branches was constructed for Atlas cedar (Cedrus atlantica Manetti). The vertical location of branches in the crown partly governs their further growth and mortality from which depend (i) the stem growth and form and (ii) the quality of lumber and veneer, including wood knots. The modeling method, based on an architectural approach, reveals branching patterns. Each annual shoot was considered as a sequence of successive positions, unbranched or branched with two types of branch: short or long shoot. Branching sequences were analyzed using hidden semi-Markov chains. A wide range of annual shoot lengths was sampled in order to determine the relationships between sequence length and the characteristics of every zone identified (frequency of every type of axillary production, probability of zone occurrence and probability of transition to the following zone). The model predicts branch vertical position which can be used as inputs for branch diameter and mortality models.
\end{abstract}

branching pattern / branch vertical location / hidden semi-Markov chain / Cedrus atlantica

Résumé - Prédiction de la position verticale des branches le long du tronc du cèdre de l'Atlas (Cedrus atlantica Manetti) en relation avec la longueur de pousse annuelle. Un modèle donnant la position verticale des branches verticillaires et interverticillaires a été établi pour le cèdre de l'Atlas (Cedrus atlantica Manetti). La position verticale des branches dans le houppier détermine en partie leur développement ultérieur et leur mortalité dont dépendent (i) la croissance et la forme de la tige et (ii) la qualité des sciages et des placages comprenant les nœuds. La méthode de modélisation, basée sur une approche architecturale, met en évidence les caractéristiques de la branchaison. Chaque pousse annuelle est considérée comme une séquence de positions successives soit sans branche, soit porteuse d'un rameau court ou long. Les séquences ont été analysées en utilisant les semichaînes de Markov cachées. Une large gamme de longueur de pousse a été échantillonnée pour évaluer les relations entre la longueur des séquences et les caractéristiques des zones identifiées (fréquence de chaque type de production axillaire, probabilité de la présence de la zone et probabilité de transition vers la zone suivante). Le modèle prédit la position verticale des branches qui peut être ensuite utilisée comme entrée de modèles de diamètre et de mortalité de ces branches.

branchaison / position verticale des branches / semi-chaîne de Markov cachée / Cedrus atlantica

\section{INTRODUCTION}

\subsection{Modeling branching patterns in trees}

Models describing branch characteristics have developed rapidly over the last fifteen years. Their interest is two-fold:

- (i) In terms of physiology, the photosynthetic capacity is directly related to the branch size. Conversely, the branches are the next place of transport and allocation of assimilates, just after the leaves. Simulating the spatial distribution of branches using architectural models provides detailed crown structure which may be used as support for process-based models, e.g. photosynthesis through the foliage distribution or sap transfer through the hydraulic network [37].

- (ii) In terms of wood quality, the diameter and the location of branches on a tree stem have a great effect on aes-

* Corresponding author: courbet@avignon.inra.fr thetic and mechanical wood properties. The insertion of primary branches on the bole results in knots which increase the heterogeneity of lumber or veneer, decrease the mechanical strength properties and are a drawback for most of wood transformations and valorization processes. The size and the spatial arrangement of the knots are very often used in the grading rules of softwood lumber (e.g. [1]). Models can thus successfully predict wood quality and simulate the quality of lumber with grading rules based on knottiness [5].

\subsection{Modeling branch location}

Branch growth and size closely depend on its vertical position along the tree bole [21,24]. In the same way, branch survival and therefore knot aspect, tight or loose, depend both on their size and position (i.e. the depth into the crown) [22].

Several authors have developed models for predicting branch location. These models may predict vertical location 

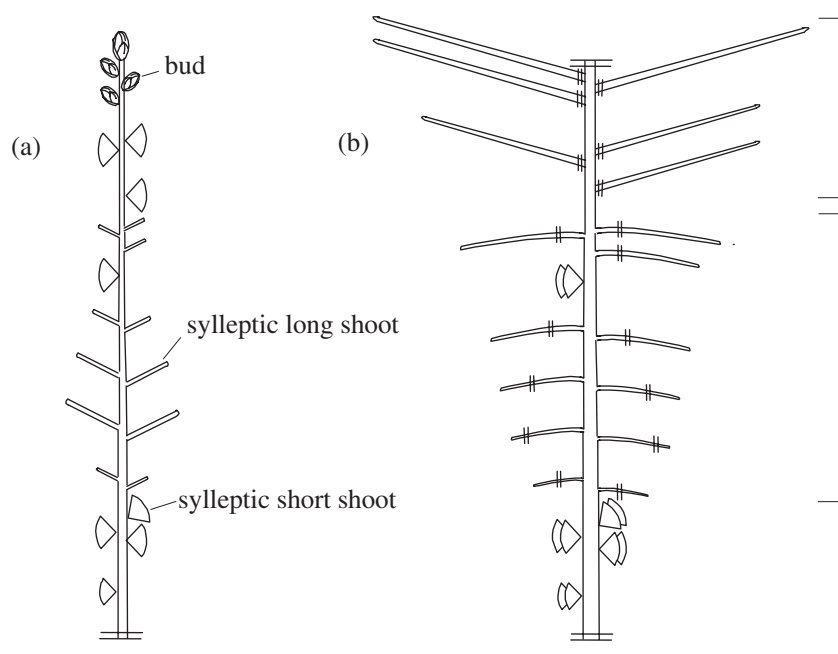

whorl branches

interwhorl branches
Figure 1. Diagrammatic representation of a oneyear-old (a) and two-year-old (b) vigorous annual shoot of the main stem of Atlas cedar. \# Annual growth limit (from [31]). along the stem and branch azimuth around the stem. Regarding vertical position, the proposed models are quite different depending on whether the species forms interwhorl branches or not.

When the species only forms whorl branches (e.g. Pinus sp.), they are usually assigned at the top of the annual shoots of the main stem (e.g. [9]). When the species forms interwhorl branches distributed all along the shoots (e.g. Picea sp., Abies sp., Larix sp., Douglas fir), the branch location model is more complex. Knowing the number of branches per shoot, the relative frequency of branches at a given relative height inside the shoot is determined using an observed distribution or a mathematical relation. For instance, a linear function was used for the interwhorl branches of Sitka spruce [6] and a multivariate linear model was used for the lateral long shoots of Larix laricina. In Douglas fir, Maguire et al. [21] used the average observed relative frequency of branches of $3 \mathrm{~mm}$ or more in diameter at a relative height on the annual shoot. This model hence assumes that a long annual shoot is a scaled-up version of a shorter shoot, with the same branch number per length unit at a constant relative height on the shoot. This model does not take into account the branching pattern within individual shoots.

Lateral branches are initiated at nodes where axial leaves occurred. Their vertical position depends on both node rank and internode length value. Pont [25] used the phyllotactic patterns to predict the spatial arrangement (i.e. height and azimuth) of Pinus radiata branches. The vertical position of the branch is equal to its ontogenetic sequential number multiplied by the estimated value of the internode length.

All these models require previous knowledge of the number of branches on every parent annual shoot. In general, models predicting the number of branches closely depend on the length of the parent shoot and sometimes on additional tree characteristics.

Recent studies in fruit trees [7, 36] and forest trees [19] have shown that branching of shoots is often organized as a succession of homogeneous zones where composition properties, in terms of type of axillary production (i.e. branches), do not change substantially within zone but change markedly between zones. Hidden Markov models are the standard statistical models for analyzing homogeneous zones within sequences or detecting transitions between zones (see [10] for a tutorial about this family of statistical models). Hidden semiMarkov chains generalize hidden Markov chain with the distinctive property of explicitly modeling the length of each zone. These statistical models enable modeling both the number and the vertical location of lateral branches [18].

\subsection{Branching patterns of Atlas cedar}

The main stem of Atlas cedar is built up by a succession of annual shoots. On the current year leader shoot, some lateral shoots sometimes immediately develop from meristems without passing through a bud phase. They are termed sylleptic shoots in contrast with the proleptic shoots that elongate from lateral buds after a resting period. Young sylleptic shoots can be thus differentiated from proleptic shoots by the lack of cataphylls at their base. The occurrence and amount of sylleptic shoots are correlated with parent shoot vigor. During the first year of growth, all the sylleptic shoots are longer when they are located in the vicinity of the middle of the parent leader shoot, showing a mesotonic gradient in length (Fig. 1a, [31]). During the following year, branches produced from lateral buds located just below the terminal bud become predominant. Along the annual shoot, an acrotonic gradient is progressively superimposed on the previous mesotonic gradient (Fig. 1b). Atlas cedar does not form annual branch whorls in a strict botanical sense. As in Douglas fir, the distinction between whorl and interwhorl branches is rather arbitrary, underscoring the pitfalls of modeling them separately [21]. On the young parent shoots, there is a progressive and regular downwards decrease of both branch diameter and length. With the future crown development, whorl branches become main branches while interwhorl branches have a shorter lifespan. In this paper, the predominant branches clustered just below the apex are termed "whorl branches", all others are called "interwhorl branches".

Branching pattern in Atlas cedar is therefore very similar to that of Larix species [28-30]. In both species, the axillary 
Table I. Stand, sample tree and shoot characteristics.

\begin{tabular}{lcccc}
\hline Attribute & Minimum Mean $\begin{array}{c}\text { Standard Maximum } \\
\text { deviation }\end{array}$ \\
\hline Stand $(n=9)$ & 335 & 2034 & 2240 & 7661 \\
Trees $\left(\right.$ ha $\left.^{-1}\right)$ & 9.9 & 19.8 & 13.4 & 30.7 \\
H50 $(\mathrm{m})$ & 8 & 41 & 26.4 & 83 \\
Age (year) & 14.6 & 35.8 & 20.3 & 71.3 \\
$\mathrm{~S}^{2}(\%)$ & 4 & 7.2 & 8.2 & 22 \\
Number of sample trees per stand & 22 & 36 & 8 & 49 \\
Number of sample shoots per stand & & & & \\
Tree $(n=74)$ & 0 & 11.1 & 12.3 & 71.9 \\
DBH (cm) & 1.1 & 6.9 & 6.0 & 27.3 \\
Total height (m) & 8 & 30.2 & 25.6 & 83 \\
Age (year) & 1 & 4.4 & 4.4 & 21 \\
Number of sample shoots per tree & & & & \\
Annual shoot $(n=324)$ & 2.4 & 24.1 & 16.7 & 81.2 \\
Length $(\mathrm{cm})$ & 2 & 11.8 & 8.3 & 39 \\
Age (year) & 3 & 22.2 & 13.9 & 69 \\
Number of lateral shoots & 1 & 13.9 & 12.4 & 60 \\
Number of lateral long shoots & 1 & 8.6 & 5.1 & 30 \\
Number of lateral short shoots & & &
\end{tabular}

${ }^{1}$ Top heigth at age 50.

${ }^{2} S=10746 / H 0 \sqrt{N}$ where $N$ is the number of trees per ha and $H 0$ is the top height in $\mathrm{m}$ ).

branches comprise two types of axes: long shoots and short shoots (Fig. 1b). Short shoots tend to be located on the proximal part of parent shoots $[28,31]$. They elongate about one millimeter per year and form each year a spiral cluster of needles. In general, short shoots located on the main axis survive only 3 or 4 years because of lack of light.

A positive correlation between the number of axillary branches and parent shoot length has been found in conifers [3] and in particular in cedar [8, 31]. However the effect of parent shoot length on the branching pattern has not been reported. A previous study [23] has shown that:

- (i) branching pattern is correctly represented by a hidden semi-Markov chain in Cedrus atlantica,

- (ii) branch distribution along the annual shoot does not change with site index or stand density.

The aim of this study is to analyze the branching pattern of Atlas cedar in order to develop a static model which accounts for the vertical position of the primary branches inserted along the stem. The production of axillary branches was analyzed on a wide range of parent shoot lengths in the form of sequences in order to explore and model the effect of the parent annual shoot length on the distribution of the lateral branches.

\section{MATERIALS AND METHODS}

\subsection{Data acquisition}

\subsubsection{Site, stand and tree measurements}

A total of 74 trees were selected from 9 even-aged stands in the south-east of France (6 in the Vaucluse district, 2 in the Aude district and 1 in the Gard district). The stands were chosen to be as different as possible in terms of growth conditions (i.e. age, density and site index) in order to sample a wide range of shoot lengths. The site index (i.e. top height at age 50), was calculated by a specific top height growth model [11]. The stand density was expressed by the HartBecking relative spacing index $(S=10746 / H 0 \sqrt{N})$ where $N$ is the number of trees per ha and $H 0$ is the top height in meters). Trees in each stand were chosen to cover the range of diameters present in the stand as well a wide range of shoot lengths.

\subsubsection{Annual shoot measurements}

The annual shoots were selected on each tree from the top to the base as follows:

- one annual shoot every three years starting from two-year-old annual shoot,

- annual shoots without branch pruning,

- annual shoots without evident damage which can affect the branching pattern (e.g. [27]).

Characteristics of the stands, sample trees and shoots are summarized in Table I.

The main stem annual shoots always pass through a bud phase before developing. On young shoots, their limits could be retrospectively detected by scales or scale scars left by the scaly leaves of the bud that have fallen down. With axis ageing, these scars progressively disappeared. The insert point of the highest branch, which is very frequently the thickest branch of the shoot, was then considered as the top limit of the annual shoot. An annual shoot of the stem is thus delimited (i) upwards by its highest branch, (ii) downwards by the highest branch of the previous annual shoot. The annual shoots of the main stem were identified and every lateral branch was assigned its parent shoot. The height of insert point of each lateral branch to the trunk was measured to the nearest millimeter. The insert angle of every branch was measured to the nearest 5 grades. The circumference outside bark of every shoot (not only the sampled ones) was measured avoiding any deformations due to branches. For each sampled parent shoot, the nature (i.e. long or short) of every lateral shoot was also recorded. Because the scars of cataphylls disappear after one or two years of growth, the proleptic shoots could not be identified a posteriori and thus were not differentiated from the sylleptic shoots.

\subsubsection{Sequence construction}

The height of insert point of every branch was then corrected in order to calculate its insert height at the pith level (i.e. when the branch formed) to avoid errors associated with branch angle and stem growth, by the following formula:

$$
h r=h m-\left[\frac{r_{i+1}-\left(r_{i+1}-r_{i}\right)\left(\frac{h m-h_{i+1}}{h_{i}-h_{i+1}}\right)}{\operatorname{tg} \alpha}\right]
$$

where $h r$ is the calculated height of insert point of the branch to the pith, $h m$ is the measured height of insert point of the branch to the trunk, $r_{i+1}$ is the radius of the stem measured below the branch at height $h_{i+1}, r_{i}$ is the radius of the stem measured above the branch at height $h_{i}$ and $\alpha$ is the branch insertion angle (Fig. 2).

The depth of each branch into the parent shoot was calculated by the distance $d r$ to the highest branch of the shoot (i.e. the difference 


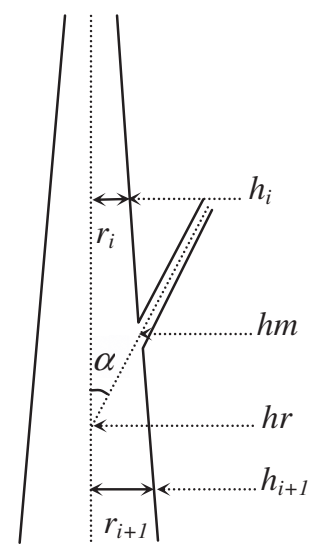

Figure 2. Variables used to calculate the insert height of the branches to the pith level. $h r$ is the calculated insert position of the branches to the pith level: $\mathrm{hm}$ is the measured position of the branch inserted on the trunk, $r_{i+1}$ is the radius of the stem measured below the branch at the height $h_{i+1}, r_{i}$ is the radius of the stem measured above the branch at the height $h_{i}$ and $\alpha$ is the branch insertion angle.

between the height of insert point of the highest branch and the height of insert point of the branch of interest).

In every annual shoot of the stem, the branches were ordered from the top to the base according to increasing $d r$.

\subsubsection{Discretization}

For the analysis of branching structures, the natural index parameter of the branching sequences is the node rank. This cannot be easily applied to cedars due to the size of the internodes and because the node scars can no more be detected after few years of main axis development. The statistical modeling based on hidden semi-Markov chains relies heavily on the discrete nature of the index parameter and cannot be transposed to sequences with a continuous index parameter like height. Hence we chose to discretize the branching sequences by defining a working index parameter which is close to the smallest length between two successive branches. Its value $d r$ was then rounded to the nearest $4 \mathrm{~mm}$ which was the value chosen by Masotti et al. [23] for Atlas cedar.

In the following, we will thus use the term position (instead of node), a position being either unbranched or branched (distinguishing different types of branches, i.e. short or long shoots). In this way discrete time stochastic processes such as hidden semi-Markov chains can still be applied.

Each annual shoot was thus considered as a discrete sequence of successive positions separated by $4 \mathrm{~mm}$ length steps. Each position was characterized by a type of axillary production coded as follows: (0): no axillary production (i.e. unbranched position), (1): short shoot, (2): long shoot. Henceforth, the different types of axillary production will be termed "event".

While the macroscopic structure taking the form of a succession of branching zones is not affected by the discretization, more local patterns such as for instance the succession of branched or unbranched positions within a zone are strongly affected by the discretization. The probabilities of observing a branching type depends on the discretization step but the ratio between probabilities of observing short
Table II. Frequency and mean length of branching sequences according to classes of sequence length.

\begin{tabular}{lcc}
\hline $\begin{array}{l}\text { Length class } \\
\text { (in number of positions) }\end{array}$ & Frequency & $\begin{array}{c}\text { Mean length } \\
\text { (in number of positions) }\end{array}$ \\
\hline $1-20$ & 42 & 14.64 \\
$21-40$ & 58 & 31.05 \\
$41-60$ & 62 & 51.23 \\
$61-80$ & 54 & 69.35 \\
$81-120$ & 50 & 96.62 \\
$121-160$ & 33 & 139.09 \\
$161-221$ & 25 & 183.16 \\
\hline
\end{tabular}

shoot and long shoot are roughly conserved for different discretization steps.

\subsection{Data analysis}

The annual shoots were grouped by length classes (in number of positions) in order to investigate the effect of parent shoot length on the branching pattern. Classes sizes were chosen in order to ensure a sufficient number of shoots per class (Tab. II).

Statistical methods described hereafter for building hidden semiMarkov chains from samples of discrete sequences have been developed [15-17] and integrated in the AMAPmod software [13,14]. The analysis was performed using AMAPmod on each group of shoots.

\subsubsection{Exploratory analysis}

The characteristics of a sample of sequences take the form of families of frequency distributions [18]. These characteristics are organised in three categories (see Fig. 3 for an example):

- "Intensity": the empirical event distribution is extracted for each successive position from a sample of sequences. Changes in distribution of events as a function of the position make it possible to evaluate the dynamics of the phenomenon studied, such as the locations of the main transitions between homogeneous zones.

- "Interval": for each possible event, the three following types of interval can be extracted from a sample of sequences:

(i) time to the first occurrence of an event, i.e. the number of transitions before the first occurrence of this event,

(ii) recurrence time, i.e. the number of transitions between two occurrences of an event,

(iii) sojourn time ("run length" of an event), i.e. the number of successive occurrences of a given event.

- "Counts": the number of occurrences of a given pattern is extracted for each sequence. The two patterns of interest are the occurrence of a given event as well as the "run" (or clump) of a given event as defined above.

Families of characteristic distributions can play different roles in this kind of analysis. The empirical probabilities of the events as a function of the position (intensity) give an overview of process "dynamics". This overview is complemented for the initial transient phases by the distributions of the time up to the first occurrence of an event. Local patterns in the succession of events are expressed in (i) recurrence time distributions, (ii) sojourn time distributions and 


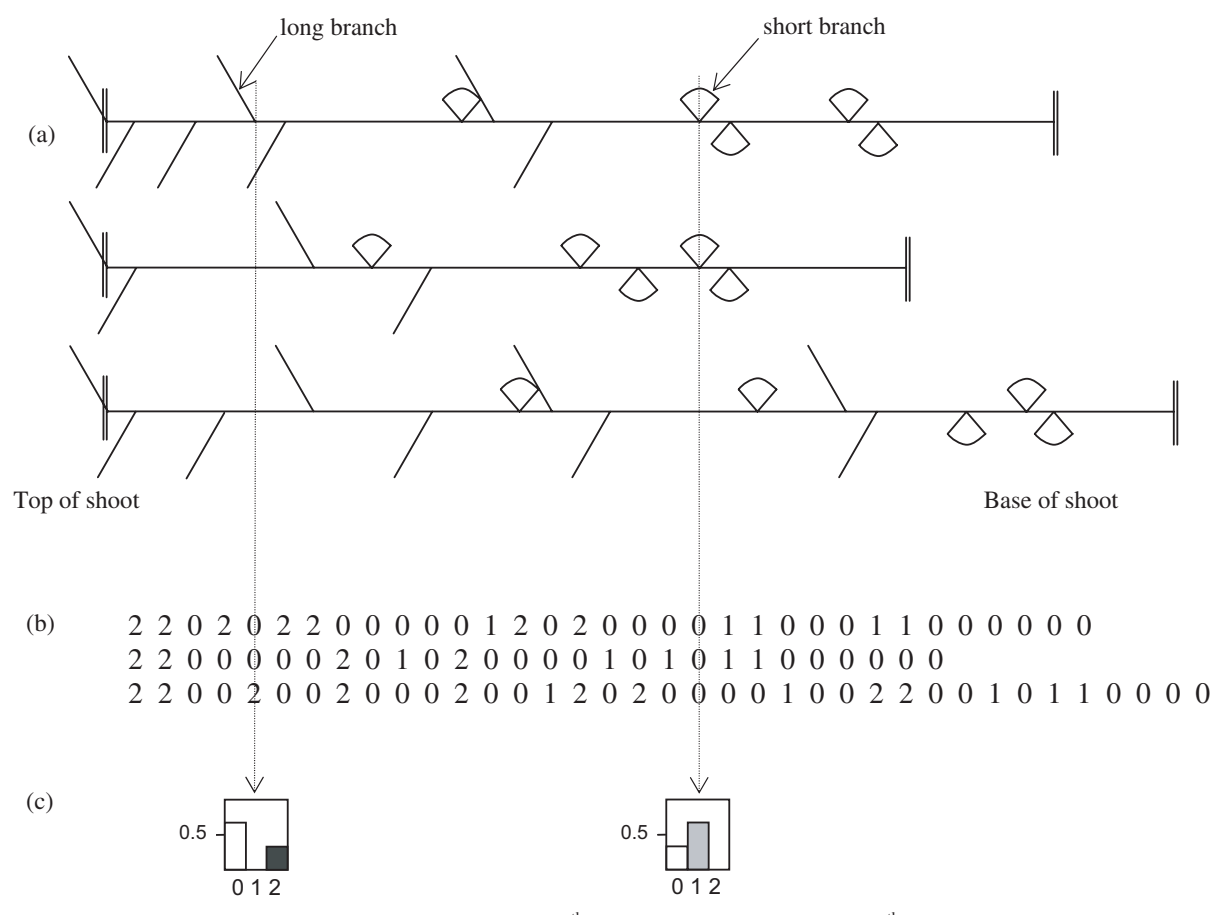

Relative frequencies of the three events at the $5^{\text {th }}(0: 0.67 ; 1: 0 ; 2: 0.33)$ and $20^{\text {th }}$ rank $(0: 0.33 ; 1: 0.67 ; 2: 0)$ on the basis of the three sequences

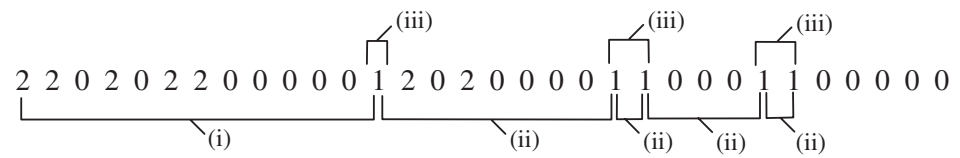

For the event "1" (i.e. short branch):

(i) 12 transitions before the first occurrence,

(ii) 4 recurrence times of length $8,1,4$ and 1 ,

(iii) 3 runs of length 1,2 and 2 ( 5 occurrences in the sequence).

Figure 3. Exploratory analysis of a sample of three shoots (21-40 position length class). (a) Diagrammatic representation of shoots (b) Coding of the discretized sequences $(0=$ position without branch, $1=$ position with short shoot, 2 = position with long shoot). (c) Extraction of the "intensity" characteristics: the frequencies of the three events were calculated for the different positions. (d) For the first sequence: extraction of the "interval" characteristics (i) time up to the first occurrence of an event, (ii) recurrence time, i.e. number of transitions between two occurrences of an event, (iii) sojourn time, i.e. number of successive occurrences of a given event ("run length" of an event) and "count" characteristics (number of occurrences and number of runs of an event per sequence).

(iii) the distributions of the number of runs of an event per sequence. These three types of characteristic distribution can help to highlight, otherwise scattered or aggregate distributions of a given event along sequences.

\subsubsection{Statistical modeling}

The structure of a hidden semi-Markov chain can be described as follows. The underlying "left-right" semi-Markov chain (i.e. composed of a succession of transient states and a final absorbing state) represents both the succession of homogeneous zones and the length, in number of positions, of each zone. Each zone is represented in the semi-Markov chain by a mathematical object called a state. A state is said to be transient if after leaving this state, it is impossible to return to it. A state is said to be absorbing, if after entering this state, it is impossible to leave it. A discrete distribution of the events (i.e. axillary production types) is associated with each state. A hidden semi-Markov chain is thus defined by four subsets of parameters (Fig. 4):

- initial probabilities of being in a given state at the beginning of the sequence,

- transition probabilities to model the succession of states along the shoot (the transitions probabilities leaving a given state to the possible following states sum to one),

- occupancy distributions attached to non-absorbing states to model zone length (in number of positions),

- observation distributions to model the composition properties within the zones in terms of axillary production types.

The analyses were performed twice:

- (i) on the sequences described upwards from the base to the top, 
(a)

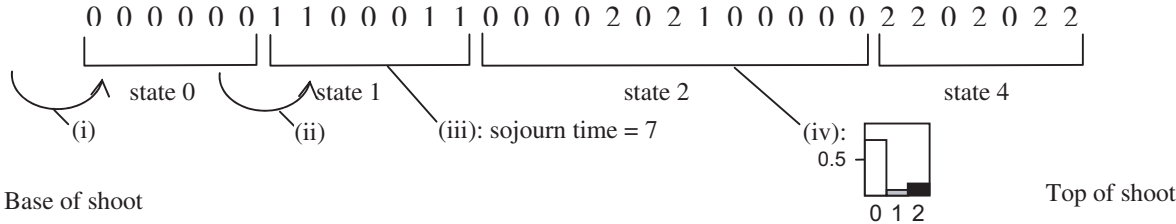

(b)

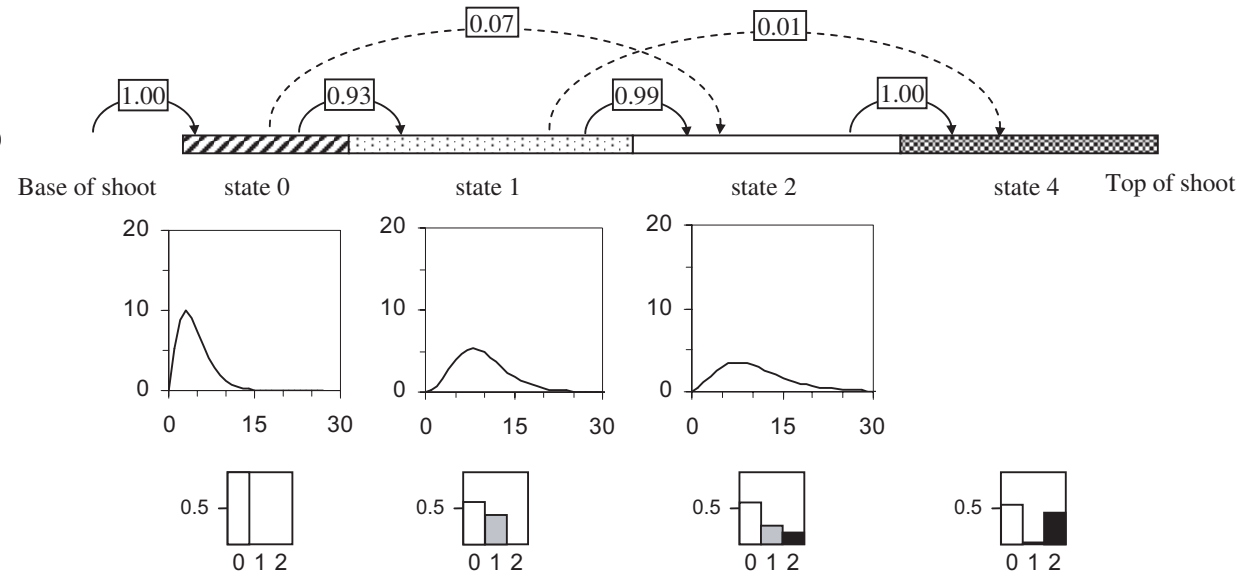

Figure 4. (a) A 33-position length shoot, its observed sequence $(0=$ no production, $1=$ short shoot, $2=$ long shoot $)$ and the associated states. (i) Selection of the initial state, (ii) transition between the states, (iii) occupancy (or sojourn time) in the state, (iv) empirical observation distributions (0: $0.77 ; 1: 0.08 ; 2$ : 0.15$)$. It can be noted that the state 3 does not occur on this short shoot. (b) Example of the estimated hidden semi-Markov chain for the 21-40 nodes length class. Each state - 0, 1, 2, 4 from left to right - is represented by a rectangle whose length is proportional to the mean of sojourn time (mean of the number of successive positions in the state). The possible initial state and the transitions between states are represented by arrows with the attached probability noted nearby. Under each state lies an associated graphic which represents the occupancy distribution of the state. At the bottom, an histogram represents the frequencies of the different types of axillary productions of the state.

- (ii) on the sequences described from the top to the base so that the final absorbing state upwards (for which an occupancy distribution cannot be estimated) was the initial state downwards in order to model the length of the top zone.

The core of the proposed data analysis methodology consists in iterating an elementary loop of model building until a satisfactory result is obtained. This elementary loop decomposes into three stages:

(i) Model specification: This stage consists mainly in dimensioning the embedded semiMarkov chain (i.e. determining the number of states: models with 4 and 5 states were tried) and in making hypotheses on its structural properties on the basis of the characteristic distributions extracted from the observed sequences. Structural constraints are expressed by prohibiting transitions i.e. by setting the corresponding probabilities to zero. Using the same principle, constraints can also be expressed on the initial probabilities and the observation probabilities.

(ii) Model inference: The maximum likelihood estimation of the parameters of hidden semi-Markov chains requires an iterative optimization technique which is an application of the ExpectationMaximization (EM) algorithm [16,17].

(iii) Model validation: The accuracy of the estimated model is mainly evaluated by the fit of characteristic distributions computed from model parameters to the corresponding empirical characteristic distributions extracted from the observed sequences $[15,16,18]$.
Once the hidden semi-Markov chain has been estimated [16, 17], the most probable state sequence was computed using the so-called Viterbi algorithm [16] for each observed sequence. This most probable states sequence can be interpreted as the optimal segmentation of the observed sequence in successive zones (an observed sequence segmented into successive states is presented in Fig. 4a while an example of model parameters is presented in Fig. 4b). The statistical modeling was performed on each sequence length group.

\subsubsection{Modeling the zone length}

The length (in number of positions) of each branching zone was recovered sequence by sequence as results of the optimal segmentation. In order to model the length of each simulated zone, we examined the relationship between the total sequence length and the length of each zone. The zone length corresponds to the sojourn time in the corresponding state.

Two kinds of model were then built in order to predict every zone length:

- For the zones whose length varied in a wide range of values and followed a normal distribution, a model was fitted to data using the ordinary least squares method or, when necessary, the weighted least squares method in order to ensure the homoscedastic variance of the residuals. The model was chosen to be linear or segmented linear according to the trends revealed by data plots. Fits were performed by the REG or NLIN procedures of the SAS/STAT software [34]. 
Table III. Observation probabilities of different types of axillary production per state according to sequence length classes and direction of description.

\begin{tabular}{|c|c|c|c|c|c|c|c|c|c|}
\hline State & $\begin{array}{l}\text { Direction of } \\
\text { description }\end{array}$ & $\begin{array}{c}\text { Type of axillary } \\
\text { production }\end{array}$ & $\begin{array}{c}1-20 \\
\text { positions }\end{array}$ & $\begin{array}{c}21-40 \\
\text { positions }\end{array}$ & $\begin{array}{c}41-60 \\
\text { positions }\end{array}$ & $\begin{array}{c}61-80 \\
\text { positions }\end{array}$ & $\begin{array}{c}81-120 \\
\text { positions }\end{array}$ & $\begin{array}{l}121-160 \\
\text { positions }\end{array}$ & $\begin{array}{l}161-221 \\
\text { positions }\end{array}$ \\
\hline \multirow[t]{3}{*}{0} & \multirow[t]{3}{*}{ Upwards } & 0: no branch & 1.00 & 1.00 & 1.00 & 1.00 & 1.00 & 1.00 & 1.00 \\
\hline & & 1: short shoot & 0.00 & 0.00 & 0.00 & 0.00 & 0.00 & 0.00 & 0.00 \\
\hline & & 2: long shoot & 0.00 & 0.00 & 0.00 & 0.00 & 0.00 & 0.00 & 0.00 \\
\hline \multirow[t]{3}{*}{1} & \multirow[t]{3}{*}{ Upwards } & 0: no branch & 0.52 & 0.59 & 0.62 & 0.61 & 0.61 & 0.55 & 0.62 \\
\hline & & 1: short shoot & 0.48 & 0.41 & 0.38 & 0.39 & 0.39 & 0.45 & 0.38 \\
\hline & & 2: long shoot & 0.00 & 0.00 & 0.00 & 0.00 & 0.00 & 0.00 & 0.00 \\
\hline \multirow[t]{6}{*}{2} & \multirow[t]{3}{*}{ Upwards } & 0: no branch & 0.25 & 0.58 & 0.64 & 0.66 & 0.68 & 0.62 & 0.59 \\
\hline & & 1: short shoot & 0.45 & 0.26 & 0.18 & 0.14 & 0.12 & 0.11 & 0.14 \\
\hline & & 2: long shoot & 0.30 & 0.16 & 0.18 & 0.20 & 0.20 & 0.27 & 0.27 \\
\hline & \multirow[t]{3}{*}{ Downwards } & 0: no branch & 0.59 & 0.63 & 0.64 & 0.66 & 0.69 & 0.56 & 0.59 \\
\hline & & 1: short shoot & 0.16 & 0.15 & 0.12 & 0.10 & 0.11 & 0.16 & 0.15 \\
\hline & & 2: long shoot & 0.25 & 0.22 & 0.25 & 0.24 & 0.20 & 0.28 & 0.26 \\
\hline \multirow[t]{6}{*}{3} & \multirow[t]{3}{*}{ Upwards } & 0: no branch & - & - & - & - & 0.71 & 0.72 & 0.75 \\
\hline & & 1: short shoot & - & - & - & - & 0.02 & 0.01 & 0.01 \\
\hline & & 2: long shoot & - & - & - & - & 0.27 & 0.27 & 0.24 \\
\hline & \multirow[t]{3}{*}{ Downwards } & 0: no branch & - & - & - & - & 0.72 & 0.71 & 0.75 \\
\hline & & 1: short shoot & - & - & - & - & 0.00 & 0.02 & 0.01 \\
\hline & & 2: long shoot & - & - & - & - & 0.28 & 0.27 & 0.24 \\
\hline \multirow[t]{3}{*}{4} & \multirow[t]{3}{*}{ Downwards } & $0:$ no branch & 0.05 & 0.03 & 0.03 & 0.00 & 0.00 & 0.32 & 0.54 \\
\hline & & 1: short shoot & 0.04 & 0.04 & 0.00 & 0.00 & 0.00 & 0.00 & 0.00 \\
\hline & & 2: long shoot & 0.91 & 0.93 & 0.97 & 1.00 & 1.00 & 0.68 & 0.46 \\
\hline
\end{tabular}

- For the zones whose length ranged within only few discrete values or followed a distribution different from the normal distribution, a generalized linear model was estimated using a maximum likelihood method. The length values $x$ were therefore previously converted in $\log (x-1)$ in order to make them varying from $-\infty$ to $+\infty$. These analyses were performed with the Genmod procedure of the SAS/STAT software [34].

\section{RESULTS}

\subsection{Structure of the estimated hidden semi-Markov chains}

On the basis of both the exploratory analysis of the data and the statistical modeling, the following assumptions were made:

All the estimated models began with an initial state corresponding to an unbranched zone at the base of the annual shoot and ended with an absorbing state which corresponds to long branches at the tip of the annual shoot. Between these two states, the models comprises between 1 to 3 transient states according to the length of branching sequences.

\subsection{Composition of the states}

Branching states were well-differentiated in terms of axillary production type composition. The probabilities of observing the different types of axillary production, for every state and length class, are reported in Table III. Five successive states were identified:
- State 0 corresponded to the initial unbranched zone,

- State 1 corresponded to a poorly branched zone with short shoots,

- State 2 corresponded to a zone with a mixture of short and long shoots.

These first three states occurred in each group of sequences.

- State 3 corresponded to a zone with almost only long shoots. This zone only occurred for the sequences whose length exceeded 80 positions.

- State 4 corresponded to a zone with a high probability of long shoots which probably correspond to the whorl branches. It was only modeled on the sequences described from the top to the base. This zone was present whatever the sequence length.

Each state (or zone) was so defined by the probabilities of observing the different types of axillary production which was rather stable with the length of the sequences. There were only two exceptions:

- (i) State 2 in the shortest sequences (1-20 positions), for which the frequency of branched positions was greater than in the longer sequences,

- (ii) State 4 where the frequency of unbranched positions was higher for the sequences whose length exceeded 120 positions.

The branching type composition of states 2 and 3 remained unchanged whatever the description direction, excepted for state 2 in the case of the shortest sequences (1-20 positions).

For the model, we decided to retain the probabilities associated with the description direction which corresponds to the branch setting: upwards for states $0,1,2$ and 3, set during the 
Table IV. Parameters of hidden semi-Markov chains estimated for different sequence length classes: initial probabilities and transition probabilities between successive states in the sequence, according to direction of description.

\begin{tabular}{|c|c|c|c|c|c|c|c|c|c|}
\hline $\begin{array}{l}\text { Direction of } \\
\text { description }\end{array}$ & $\begin{array}{l}\text { Initial or } \\
\text { transition }\end{array}$ & $\begin{array}{c}\text { States } \\
\text { concerned }\end{array}$ & $\begin{array}{c}1-20 \\
\text { positions }\end{array}$ & $\begin{array}{c}21-40 \\
\text { positions }\end{array}$ & $\begin{array}{c}41-60 \\
\text { positions }\end{array}$ & $\begin{array}{c}61-80 \\
\text { positions }\end{array}$ & $\begin{array}{c}81-120 \\
\text { positions }\end{array}$ & $\begin{array}{l}121-160 \\
\text { positions }\end{array}$ & $\begin{array}{l}161-221 \\
\text { positions }\end{array}$ \\
\hline \multirow[t]{10}{*}{ Upwards } & \multirow[t]{3}{*}{ Initial } & 0 & 1.00 & 1.00 & 0.95 & 1.00 & 1.00 & 1.00 & 0.94 \\
\hline & & 1 & 0.00 & 0.00 & 0.01 & 0.00 & 0.00 & 0.00 & 0.02 \\
\hline & & 2 & 0.00 & 0.00 & 0.04 & 0.00 & 0.00 & 0.00 & 0.04 \\
\hline & \multirow[t]{7}{*}{ Transition } & from 0 to 1 & 0.89 & 0.93 & 0.98 & 0.90 & 0.88 & 0.86 & 0.95 \\
\hline & & from 0 to 2 & 0.11 & 0.07 & 0.02 & 0.10 & 0.12 & 0.14 & 0.05 \\
\hline & & from 1 to 2 & 0.47 & 0.99 & 1.00 & 1.00 & 0.81 & 0.88 & 0.78 \\
\hline & & from 1 to 3 & - & - & - & - & 0.19 & 0.12 & 0.22 \\
\hline & & from 1 to 4 & 0.53 & 0.01 & 0.00 & 0.00 & 0.00 & 0.00 & 0.00 \\
\hline & & from 2 to 3 & - & - & - & - & 0.73 & 1.00 & 1.00 \\
\hline & & from 2 to 4 & 1.00 & 1.00 & 1.00 & 1.00 & 0.27 & 0.00 & 0.00 \\
\hline \multirow[t]{8}{*}{ Downwards } & \multirow[t]{3}{*}{ Initial } & 4 & 1.00 & 1.00 & 1.00 & 0.98 & 0.98 & 1.00 & 1.00 \\
\hline & & 3 & 0.00 & 0.00 & 0.00 & 0.02 & 0.00 & 0.00 & 0.00 \\
\hline & & 2 & 0.00 & 0.00 & 0.00 & 0.00 & 0.02 & 0.00 & 0.00 \\
\hline & \multirow[t]{5}{*}{ Transition } & from 4 to 3 & - & - & - & - & 0.88 & 1.00 & 1.00 \\
\hline & & from 4 to 2 & 1.00 & 0.98 & 1.00 & 1.00 & 0.12 & 0.00 & 0.00 \\
\hline & & from 4 to 1 & 0.00 & 0.02 & 0.00 & 0.00 & 0.00 & 0.00 & 0.00 \\
\hline & & from 3 to 2 & - & - & - & - & 0.93 & 1.00 & 0.97 \\
\hline & & from 3 to 1 & - & - & - & - & 0.07 & 0.00 & 0.03 \\
\hline
\end{tabular}

elongation of the parent shoot, and downwards for the last state 4 initiated by the height growth stop.

\subsection{Initial and transition probabilities}

The initial probabilities of each state and the probabilities of transition between two consecutive states are given in Table IV. Almost all the estimated sequences began in state 0 , and very rarely in state 1 or 2 . The final state, or downwards the initial one, was almost always the state 4 , exceptionally the state 3 or 2 . The states mostly succeeded one to each other in the following order: 0-1-2-3-4 with the previously mentioned exception for the state 3 which only occurred for the sequences whose length exceeded 80 positions. Some states were sometimes skipped by the model (e.g. the state 2 for the shortest sequences with a probability of 0.53 , or the state 3 for the $81-$ 120 length group with a probability of 0.27 ). It means that these samples of sequences are heterogeneous. For instance, the state 2 did not occur for $53 \%$ of sequences of 1-20 length group.

\subsection{Relationships between the zone length and the total length of parent shoots}

The length, in number of positions, of the zones $0,1,2,3$ and 4 was compared with the total length of the considered sequence. The relationships between the length of the zones deduced from the segmentation and the length of the sequences were examined through data plots (Fig. 5). Models were fitted for the different zones according to the trends revealed by data plots.

The results are the following (Tab. V):

- Zone 0: The zone length was independent of the total sequence length (Fig. 5a). The length of the zone 0 ranged from
1 to 28 (320 observations) and followed a Poisson distribution with 6.17 positions on average.

- Zones 1 and 2: The Figures 5c and 5d clearly show a threshold effect in the relation between the length of the zone and the length of the sequence. We therefore built for both zones a segmented model by ordinary least square regression. In order to homogenize the variance which increased with the shoot length, the observations were weighted by the inverse of the squared shoot length.

- Zone 3: The length of the zone 3 is highly correlated with the sequence length $\left(R^{2}=0.78\right)$ (Fig. 5e).

- Zone 4: The length of the zone 4 ranged from 1 to 7 and was not independent of the total sequence length (Fig. 5f). The best fit was obtained by a generalized linear model with a Poisson distribution (321 observations).

\section{DISCUSSION}

This work confirms that segmentation using estimated hidden semi-Markov chains can be used to clearly identify and locate zones with homogeneous branching properties. As such, it is a useful method for analyzing branching patterns.

Based on an analysis of quantitative data, this work precisely characterized each branching zone of annuals shoots by (i) the probability for a zone to be the initial one, (ii) the probability of transition between two successive zones and (iii) the probability of each type of axillary production within a given zone. We established relationships between growth and branching patterns. Growth influences more the occurrence and the length of the zones than the axes composition of each zone. The length of every zone was modeled as a function of the length of the whole annual shoot. These parameters form a consistent model of vertical position of every branch along the trunk. 

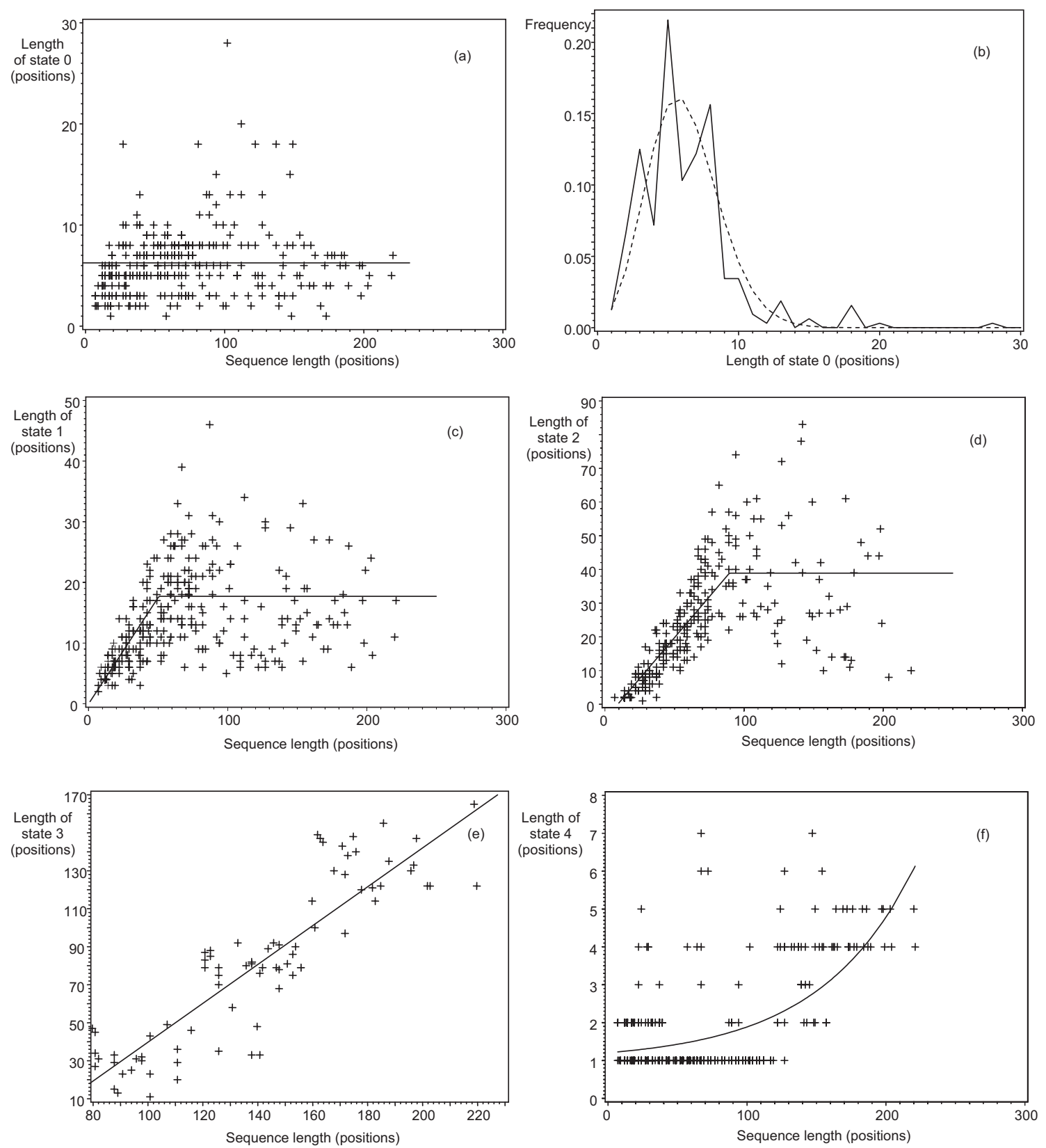

Figure 5. (a), (c), (d), (e), (f): Length of the modeled states (respectively state $0,1,2,3,4)$ vs. the total length of the observed sequence. Observed values (cross) and models associated (continuous lines). (b): Modeling the length distribution of the state 0 by a Poisson distribution. Estimated (continuous line) and modeled (dashed line) relative frequencies.

The parent shoot length has an impact on branching pattern. We found significant correlations between parent annual shoot length and branching zone length and between parent shoot length and the number of branching zones of the model. These results enhance previous results showing a simple correlation between shoot length and the number of axillary branches [23].

With regards to the identified zones, our results indeed confirm for the most part the previous qualitative observations on this species $[8,23,31,32]$. From the base to the top of the annual shoot, 5 zones were identified:
- The first two zones, the basal unbranched zone (i.e. zone 0) and the next short shoot zone (i.e. zone 1) which actually correspond to the zones previously identified by Sabatier and Barthélémy [31]. The unbranched zone remains unchanged in length, which confirms the results of Masotti et al. [23]. In contrast, the length of the short shoot zone increases with the sequence length, up to a threshold value of parent shoot length equal to 50 positions (i.e. $20 \mathrm{~cm}$ ).

- A zone with a mixture of short and long shoots (i.e. zone 2) which has never been identified before. The length of zone 2 increases with the sequence length up to a threshold 
Table V. Relationships between each zone length and the total length of parent shoots.

\begin{tabular}{|c|c|c|c|c|c|}
\hline $\begin{array}{l}\text { Zone } \\
\text { number }\end{array}$ & $\begin{array}{l}\text { Number of } \\
\text { observations }\end{array}$ & Relationship & $\begin{array}{l}\text { Distribution law } \\
\text { of the zone length }\end{array}$ & $\begin{array}{l}\text { Root mean } \\
\text { square error }\end{array}$ & $\begin{array}{c}\text { Values of } \\
\text { the parameters }\end{array}$ \\
\hline 0 & 320 & $l_{0}=a_{0}$ & Poisson & * & $a_{0}=6.17$ \\
\hline 1 & 292 & $\begin{array}{l}- \text { if } s l<s l t_{1}: l_{1}=a_{1} s l \\
- \text { if } s l \geqslant s l t_{1}: l_{1}=a_{1} s t_{1}\end{array}$ & Normal & $0.102 \mathrm{sl}$ positions ${ }^{* *}$ & $\begin{array}{c}a_{1}=0.3503 \\
s l t_{1}=50.54 \text { positions }\end{array}$ \\
\hline 2 & 264 & $\begin{array}{l}- \text { if } s l<s l t_{2}: l_{2}=a_{2} s l+b_{2} \\
- \text { if } s l \geqslant s l t_{2}: l_{2}=a_{2} s l t_{2}+b_{2}\end{array}$ & Normal & $0.130 \mathrm{sl}$ positions ${ }^{* *}$ & $\begin{array}{c}a_{2}=0.4850 \\
b_{2}=-4.499 \text { positions } \\
\text { slt }_{2}=89.49 \text { positions }\end{array}$ \\
\hline 3 & 79 & $l_{3}=a_{3} s l+b_{3}$ & Normal & 19.89 positions & $\begin{array}{c}a_{3}=1.023 \\
b_{3}=-63.79 \text { positions }\end{array}$ \\
\hline 4 & 321 & $l_{4}=\mathrm{e}^{(a 4 s l+b 4)}+1$ & Poisson & $*$ & $\begin{array}{c}a_{4}=0.01512 \\
b_{4}=-1.6220 \text { positions }\end{array}$ \\
\hline
\end{tabular}

$s l=$ shoot length in number of positions; $l_{n}=$ length of zone $\mathrm{n}$ in number of positions; $a_{0}, a_{1}, a_{2}, a_{3}, a_{4}, b_{2}, b_{3}, b_{4}, s t_{1}$ and $s t_{2}$ are parameters.

* When the variable follows a Poisson distribution, the variance is equal to the mean. For the zone 0 the variance is constant and equal to $a_{0}-1$. For the zone 4 the variance depends on the shoot length and is equal to $\mathrm{e}^{(a 4 s l+b 4)}$.

${ }^{* *}$ We used a weighted least squared method with a weight equal to $\frac{1}{s l^{2}}$. The root mean squared error is therefore proportional to $s l$.

value after which it remains constant. The threshold value for zone 2 is close to 90 and to the length class limit of 80 . Above this value, the axillary production type composition remains unchanged.

- A zone 3 which is almost exclusively branched with long shoots. Its length ranges between 11 and 165 positions and forms the most part of the long sequences. The length of this zone is closely related to the total length of the shoot. A threshold effect was noted: this state only occurs for sequences of length greater than 80 positions (i.e. $32 \mathrm{~cm}$ ). This result is consistent with previous observations on Atlas cedar [32] which showed that sylleptic lateral shoots occurred when an extension rate threshold was reached by the parent shoot of the main stem. The long shoot zone length then linearly increases with the sequence length, but with a remarkable stability of the long shoots frequency, whatever the direction of the description (Tab. III and Fig. 5e). Long shoots in this zone correspond to interwhorl branches.

The extension threshold value for sylleptic long shoot production is higher than for sylleptic short shoot production [32]. The parent shoot starts to produce sylleptic short shoots before sylleptic long shoots. Sylleptic long shoots occur when the extension rate of the parent shoot is maximum, i.e. in the middle of the parent shoot and only on the long parent shoots. Zone 3 , almost exclusively branched with long shoots, corresponds very likely to the sylleptic branched zone. As for Larix laricina [26], the occurrence and amount of sylleptic long shoots are correlated with shoot vigor and depend on growth conditions.

- The final zone (i.e. zone 4) includes long shoots with a higher probability than in the previous zone. This probability which is near 1 for a sequence length between 1 and 120 positions, diminished for the longest sequences.
Sabatier and Barthélémy [31] distinguished in the 1-yearold parent shoot, a distal zone of sylleptic short shoots preceding the buds in subapical positions. In our study short shoots were not distinguishable from buds on parent shoots over one year old. During the second growing season, these lateral short shoots and buds probably transform into the branches of zone 4. The occurrence of these short shoots might explain the longer zone 4 and the different long shoot frequencies for this zone on the most vigorous shoots (Tab. III and Fig. 5f). This zone corresponds to the whorl branches whose height assignment appears to be determined by the shoot growth decrease preceding the shoot growth stop.

The type and number of lateral branches thus depend on threshold values of both final length and extension rate of the parent shoot.

The extension of an annual shoot is followed by the formation of a resting bud consisting in a set of primordial organs. These preformed organs [2] extend during the growth period following that of their inception. A shoot may also grow in length by developing neoformed organs, i.e. a shoot portion which differentiates and extends without ever integrating a resting bud. In temperate species, an annual shoot may be entirely preformed or may be a mixed shoot, consisting of a proximal set of preformed organs and a distal set of neoformed organs [2].

In cedar, on the basis of both our results on the relationship between the branching pattern and parent shoot length and from morphological observations of cedar buds in the rest period [12], it can be assumed that the basal unbranched zone (zone 0 ) corresponds to the stem portion preformed in the bud. Its length is indeed independent of the total shoot length. The other zones of branching probably form during the current growing season. Their expression and their length result from 
the growth rate of the parent shoot. In particular, the great extent of the neoformed zone 3 in the annual shoots of the main stem expresses the adaptive potential of Atlas cedar to varying environmental conditions and its ability to exploit favorable site and climatic conditions [33]. Similarly, hidden semiMarkov chains applied to branching data in Quercus rubra showed a high correlation between the branched zone length and the summer shoot length of bicyclic annual shoots, which only occurs in favorable growth conditions [19].

\section{Use of the model}

Our model positions all the branches more precisely along the stem than the simpler models which only locate the whorl branches at the top of every shoot. These models can be sufficient for the genus Pinus which forms only whorl branches. This model was easier to build than models based on real phyllotaxy which require measuring the vertical position of all real nodes and lateral shoots the year they were formed on leaders.

Contrary to the models which predict first the number of branches and then assign to each branch a height along the main stem (e.g. [21]), this model predicts at once both characteristics according to the length of the annual shoots of the main stem. The model uses (i) the probability for a state to be the initial one, (ii) the probability of transition between two consecutive states (Tab. IV). The length of each zone is then determined by the length of the whole shoot according to the relationship found between them. The resulting relationships can therefore be connected to height tree annual increments, predicted by an existing height growth model, not yet published. The residual error of each zone length model is correctly estimated. This information can be used to generate stochastic variability around the predicted values. Nevertheless, the model must satisfy the following constraint: the length of the annual shoot must equal the sum of lengths of each zone from the same annual shoot. When it does not, the error can be distributed proportionally to each zone length or distributed only on zones for which a great accuracy is not required: e.g. if the objective is to precisely locate whorl branches, which are the biggest branches of the crown and support the greatest part of leaf biomass, then the whorl branch zone will be excluded from error redistribution.

The proportion of short shoots, long shoots and unbranched positions are finally chosen in every zone according to the probabilities in Table III.

It may be necessary to know the precise location of every branch in order to assess the aesthetical or mechanical quality of lumber or veneer, which depends on the amount and the spatial arrangement of knots, one from each other. To precisely locate a branch requires knowing not only its vertical position on the bole but also its circular position, i.e. the azimuth of the insert point of the branch around the tree bole. Cannel and Bowler [4] found that Picea and Larix branches are evenly spaced around the bole and that two successive lateral branches are rarely at less than $45^{\circ}$ one from each other. Doruska and Burkhart [9] noted a regular distribution of Pinus taeda branches around the bole. Cochrane and Ford [6] did the same observation for whorl branches as well as interwhorl branches in Sitka spruce. Pont [25] used in Pinus radiata a more realistic model based on phyllotaxy: the azimuth is equal to the branch position (i.e. the ontogenetic sequential number, equal to 0 for the first branch) multiplied by the divergence angle of $137.5^{\circ}$ which corresponds to the phyllotactic pattern defined by the Fibonacci sequence. This model could possibly be assumed to be general enough to be applied to Cedrus atlantica although we have no data for confirmation.

Branch diameter is a complementary attribute which is important in evaluating the quality and value of logs in general. Branch diameter is closely related to branch vertical position inside the living crown as well as in the annual shoot. A future model predicting branch diameter from branch vertical position is under construction. There, branch vertical position will be estimated using the model presented here.

However, this model can not precisely locate knots on lumber surface. It could be done by coupling it to a knot form model, which locate precisely the path of the branch inside the bole (e.g. [35]), and using a virtual sawing software (e.g. [20]).

A future direction for our study would be to validate our model and measure its robustness on a sample independent from the one on which it was estimated. It would be particularly interesting to fit our model using other coniferous species with interwhorl branches such as spruces and firs and mostly larches, which also have long- and short-shoot axes.

\section{CONCLUSION}

This work completes the studies previously conducted on branching patterns in Cedrus atlantica by carrying out an analysis of quantitative data measured within a wide range of annual shoot lengths. It confirms the cedar branching pattern noted before and completes these previous observations with new independent data. The composition and the location of branching were quantified using hidden semi-Markov chains. The effect of the annual shoot length on the occurrence and the length of each branching zone was quantified. The probabilities and the relationships as a whole provide a consistent model for predicting the number and the vertical location on the bole of all the primary branches, including the interwhorl branches.

Branch survival and subsequent size mainly depend on both their vertical location in relation with the height of the living crown base and relative height in the annual shoot (e.g. [21]). Cedar is well known for having whorl branches which can become predominant with a wide diameter in the apical part of annual shoots. Whorl branches mortality is the result of intertree competition which results in living crown recession. Mortality of finer interwhorl branches is due to within-crown competition which results in self-shading among branches in the same tree crown. A model predicting branch diameter profile along the bole and a stochastic model for the branch mortality are under construction. They will complete our branch location model, thus forming a chain of models useful to evaluate precisely the influence of growth on branching and wood quality in Atlas cedar. 
Acknowledgements: this work was partially supported by a grant from the French Ministry of Agriculture (DERF Convention 01.04.37/99). We are grateful to Anne Albouy, Jacques-Olivier Fouasse, Nicolas Mariotte and Olivier Richer for technical and field assistance and to the French national forest service (ONF) for providing the sample trees. We thank Jean-Noël Candau, Bruno Fady and Roland Huc for language review and constructive suggestions on the manuscript.

\section{REFERENCES}

[1] Afnor (Association française pour la normalisation), Règles d'utilisation du bois dans les constructions, Classement visuel pour l'emploi en structure des principales essences résineuses et feuillues, NF B 52-001, 1998. 16 p.

[2] Barthélémy D., Caraglio Y., Plant architecture: a dynamic, multilevel and comprehensive approach to plant form, structure and ontogeny, Ann. Bot. (2007) (in press).

[3] Cannell M.G.R., Thompson S., Lines R., An analysis of inherent differences in shoot growth within some north temperate conifers, in: Tree physiology and Yield Improvement, CANNEL MGR and LAST F.T. (Eds.), Academic Press, London, New-York, 1976, 173205.

[4] Cannell M.G.R., Bowler K.C., Spatial arrangement of lateral buds at the time they form on leaders of Picea and Larix, Can. J. For. Res. 8 (1978) 129-137.

[5] CTBA (Centre Technique du Bois et de l'Ameublement), Choisir les sciages résineux, 1999, 8p.

[6] Cochrane L.A., Ford E.D., Growth of a Sitka spruce plantation: analysis and stochastic description of the development of the branching structure, J. Appl. Ecol. 15 (1978) 227-244.

[7] Costes E., Guédon Y., Modelling branching patterns on 1-year-old trunks of six apple cultivars, Ann. Bot. 89 (2002) 513-524.

[8] Courbet F., Albouy A., Modélisation dendrométrique de l'architecture du Cèdre de l'Atlas en peuplement, in: Bouchon J. (Ed.), Architecture des arbres fruitiers et forestiers, 23-25 novembre 1993, Montpellier, INRA Editions, Les Colloques 74 (1995) 191-207.

[9] Doruska P.F., Burkhart H.E., Modeling the diameter and locational distribution of branches within the crowns of loblolly pine tress in unthinned plantations, Can. J. For. Res. 24 (1994) 2362-2376.

[10] Ephraim Y., Merhav N., Hidden Markov processes, IEEE Trans. Inf. Theory 48 (2002), 1518-1569.

[11] Evans M.-A., Étude et modélisation de la croissance en hauteur dominante du Cèdre de l'Atlas en région méditerranéenne, Technical report, Institut National Agronomique Paris-Grignon, 1996, $21 \mathrm{p}$.

[12] Flous F., 1938., Signification des rameaux et bourgeons de Cèdre, Bull. Soc. histoire naturelle de Toulouse LXXII (1938, $2^{\mathrm{e}}$ trimestre), article XVIII, $25 \mathrm{p}$.

[13] Godin C., Guédon Y., Costes E., Caraglio Y., Measuring and analysing plants with the AMAPmod software, in: Michalewicz M.T. (Ed.), Plants to Ecosystems - Advances in Computational Life Sciences, I, 53-84, Collingwood, Victoria: CSIRO Publishing, 1997.

[14] Godin C., Guédon Y. Costes E., Exploration of a plant architecture database with the AMAPmod software illustrated on an apple tree hybrid family, Agronomie 19 (1999) 163-184.

[15] Guédon Y., Computational methods for discrete hidden semiMarkov chains, Appl. Stoch. Model. Bus. 15 (1999) 195-224.

[16] Guédon Y., Estimating hidden semi-Markov chains from discrete sequences, J. Comput. Graph. Stat. 12 (2003) 604-639.

[17] Guédon Y., Hidden hybrid Markov/semi-Markov chains, Comput. Stat. Data An. 49 (2005) 663-688.
[18] Guédon Y., Barthélémy D., Caraglio Y., Costes E., Pattern analysis in branching and axillary flowering sequences, J. theor. Biol. 212 (2001) 481-520.

[19] Heuret P., Guédon Y., Guérard N., Barthélémy D., Analysing branching pattern in plantations of young red oak trees (Quercus rubra L., Fagacae), Ann. Bot. 91 (2003) 479-492.

[20] Leban J.M., Duchanois G., SIMQUA: un logiciel de simulation de la qualité du bois, Ann. Sci. For. 47 (1990) 483-493.

[21] Maguire D.A., Moeur M., Bennett W.S., Models for describing basal diameter and vertical distribution of primary branches in young Douglas fir, For. Ecol. Manage. 63 (1994) 23-55.

[22] Mäkinen H., Colin F., Predicting the number, death, and self pruning of branches in Scots pine, Can. J. For. Res. 29 (1999) 12251236.

[23] Masotti V., Barthélémy D., Mialet I., Sabatier S., Caraglio Y., Étude de l'effet du milieu sur la croissance, la ramification et l'architecture du cèdre de l'Atlas, Cedrus atlantica (Endl.) Manetti ex Carrière, in: Bouchon J. (Ed.), Architecture des arbres fruitiers et forestiers, 23-25 novembre 1993, Montpellier, INRA éditions, Les Colloques 74 (1995) 175-189.

[24] Monserud R.A., Marshall J.D., Allometric crown relations in three northern Idaho conifer species, Can. J. For. Res. 29 (1999) 521-535.

[25] Pont D., Use of phyllotaxis to predict arrangement and size of branches in Pinus radiata, N. Z. J. For. Sci. 31 (2001) 247-262.

[26] Powell G.R., Vescio S.A., Syllepsis in Larix laricina: occurrence and distribution of sylleptic long shoots and their relationships with age and vigour in young plantation-grown trees, Can. J. For. Res. 16 (1986) 597-607.

[27] Puntieri J.G., Stecconi M., Brion C., Mazzini C., Grosfeld J., Effects of artificial damage on the branching pattern of Nothofagus dombeyi (Nothofagacae), Ann. For. Sci. 63 (2006) 101-110.

[28] Remphrey W.R., Powell G.R., Crown architecture of Larix laricina saplings: quantitative analysis and modelling of (nonsylleptic) order 1 branching in relation to development of the main stem, Can. J. Bot. 62 (1984) 1904-1915.

[29] Remphrey W.R., Powell G.R., Crown architecture of Larix laricina saplings: shoot preformation and neoformation and their relationships to shoot vigour, Can. J. Bot. 62 (1984) 2181-2192.

[30] Remphrey W.R., Powell G.R., Crown architecture of Larix laricina saplings: sylleptic branching on the main stem, Can. J. Bot. 63 (1985) 1296-1302.

[31] Sabatier S., Barthélémy D., Architecture du Cèdre de l'Atlas, Cedrus atlantica (Endl.) Manetti ex. Carrière (Pinaceae), in: Bouchon J. (Ed.), Architecture des arbres fruitiers et forestiers, 2325 novembre 1993, Montpellier, INRA éditions, Les Colloques 74 (1995) 159-173.

[32] Sabatier S., Barthélémy D., Growth dynamics and morphology of annual shoots, according to their architectural position, in young Cedrus atlantica (Endl.) Manetti ex Carrière (Pinaceae), Ann. Bot. 84 (1999) 387-392.

[33] Sabatier S., Baradat P., Barthélémy D., Intra- and interspecific variations of polycyclism in young trees of Cedrus atlantica (Endl.) Manetti ex Carrière and Cedrus libani A. Rich (Pinacae), Ann. For. Sci. 60 (2003) 19-29.

[34] SAS Institute Inc, SAS/STAT ${ }^{\circledR}$ user's guide, version 8, SAS Institute Inc, Cary, NC, USA, 2000.

[35] Samson M., Bindzi I., Kamoso L.M., Représentation mathématique des noeuds dans le tronc des arbres, Can. J. For. Res. 26 (1996) 159-165.

[36] Seleznyova A.N., Grant Thorp T., Barnett A.M., Costes E., Quantitative analysis of shoot development and branching patterns in Actinidia, Ann. Bot. 89 (2002) 471-482.

[37] West G.B., Brown J.H., Enquist B.J., A general model for the structure and allometry of plant vascular systems, Nature 400 (1999) 664-667. 